\title{
Utilization of SSR Markers for Seed Purity Testing in Popular Maize Hybrids
}

\author{
Shalu Chaudhary ${ }^{1 *}$, Shikha Yashveer ${ }^{1}$ Dinesh $^{1}$, Deepak Raj Prajapati ${ }^{2}$, \\ Pushpa Kharb ${ }^{1}$ and Mehar Chand Kamboj ${ }^{2}$ \\ ${ }^{1}$ Department of Molecular Biology, Biotechnology and Bioinformatics, COBSH, CCSHAU, \\ Hisar-125004, Haryana, India \\ ${ }^{2}$ Department of Genetics and Plant Breeding, COA, CCSHAU, Hisar-125004, Haryana, India \\ *Corresponding author
}

\section{A B S T R A C T}

\begin{tabular}{|l|}
\hline Ke y w o r d s \\
$\begin{array}{l}\text { Hybrid, Maize, Molecular } \\
\text { Markers, Identification, } \\
\text { Seed purity }\end{array}$ \\
\hline Article Info \\
\hline $\begin{array}{l}\text { Accepted: } \\
10 \text { March } 2018 \\
\text { Available Online: } \\
10 \text { April } 2018\end{array}$ \\
\hline
\end{tabular}

\section{Introduction}

Maize (Zea mays L.) is one of the most important food, feed and industrial crops globally. It is predominantly a crosspollinating species, a feature that has contributed to its broad morphological variability and geographical adaptability. Economically, the most important types of maize are grown for grain or fodder and silage production. FAO predicts that an additional $60 \mathrm{Mt}$ of maize grain will be needed from the annual global harvest by 2030 . The demand for maize as an animal feed will continue to grow faster than the demand for its use as a human food, particularly in Asia, where a doubling of production is expected from the present level of $165 \mathrm{Mt}$ to almost $400 \mathrm{Mt}$ in 2030 (Paliwal et al., 2000).

There is an increasing trend towards production of hybrid maize varieties, which offer increased yield, wide adaptability and reliability in performance and quality. However production and distribution of high quality hybrid seeds is fundamental for potential crop yield. It is estimated that the yield per hectare will decrease about $135 \mathrm{~kg}$ if the maize hybrid seed purity drop $1 \%$ (Liu et al., 2000). Genetic purity testing of seeds (i.e., 
the percentage of contamination by seeds or genetic material of other varieties or species) contributes to overall seed quality. Determining the genetic purity of hybrid seed is an essential requirement for its commercial use, since there is always a chance of contamination in the hybrid seed production plot because of pollen shedders, out crossing and physical mixtures during the subsequent handling of the harvested material.

Farmers also often complain about low quality seed and seed mixtures. Moreover the characterization of genetic stocks and varieties is mandatory for the purpose of registration with the competent authority and for granting Plant Breeder's Rights under the criteria of distinctness, uniformity and stability (DUS).

Conventional characterization of hybrids based on specific morphological and agronomic data is time consuming, restricted to a few characteristics, influenced by environmental condition and inefficient. Protein markers, seed storage proteins and isozymes have also been used to estimate genetic purity as in sunflower (Alireza 2014), maize (Dou et al., 2010) and in some flowering plants (Sinha et al., 2012).

Molecular marker assisted identification with high power of genetic resolutions has emerged as a robust technique for cultivar fingerprinting, identify profiling, estimating and comparing genetic similarity and variety protection. Among available DNA markers systems, PCR based co-dominant SSRs (also known commonly as microsatellites) are preferred for genotyping because of their reproducibility, abundance and amenability to high throughput screening. The SSR markers are of great importance for rapid assessment of hybrid and parental line seed purity (Dongre et al., 2011, 2012; Pallavi et al., 2011; Reddy et al., 2011, 2015). These markers allow the early identification of true interspecific hybrids for further evaluation and crossing, and simultaneously, enable the early disposal of non-hybrids, thus delivering substantial savings in time and resources. In recent years, many SSR markers have been developed and are publicly available (http://www.maizegdb.org/ssr.php) based on their target sequences among different maize germplasm accessions.

The primary objective of the present study was to develop the DNA fingerprints for the six popular maize hybrids and their parental lines, and to establish the basis for identification and monitoring of seed purity for these hybrids.

\section{Materials and Methods}

\section{Plant material}

For the purpose of molecular identification, six maize hybrids HQPM-1, HQPM-4, HQPM-5, HQPM-7, HM-2 and HM-4 released for commercial cultivation in different parts of India and their parental lines were selected. The $F_{1}$ seeds of these hybrids and their parental lines (Table 1) were obtained from Maize Section, Department of Genetics and Plant Breeding, Chaudhary Charan Singh Haryana Agricultural University, Hisar. Seeds of the above mentioned hybrids were grown in greenhouse. A random sample of 400 seeds of each of the hybrid representing the commercial $\mathrm{F}_{1}$ seed lot was used for testing their genetic purity.

\section{Molecular analysis}

Plant DNA was isolated from seedlings using CTAB (Doyle and Doyle 1990) protocol as follows: about $0.1 \mathrm{~g}$ of young leaf tissue for each sample was homogenized in liquid nitrogen, and incubated at $60^{\circ} \mathrm{C}$ for $30-45 \mathrm{~min}$ with $500 \mu \mathrm{L}$ of CTAB buffer (1.0M Tris-HCL $\mathrm{pH}$ 8.0, $3 \mathrm{M} \mathrm{NaCl}, 0.5 \mathrm{M}$ EDTA). Then $500 \mu \mathrm{l}$ 
24: 1 of chloroform: isoamyl alcohol mixture was added and blended thoroughly for $5 \mathrm{~min}$. After centrifugation (5 min, $13000 \mathrm{rpm}$ ), aqueous layer was pipetted into a new Eppendorf tube and an approximately equal volume of cold ethanol was added. After storage at $-20{ }^{0} \mathrm{C}$ for $30-60 \mathrm{~min}$, precipitated DNA was centrifuged, air dried and finally stored in TE buffer.

For fingerprinting, DNA from the bulk leaf samples of 2 to 5 individual plants was used. Quantification of DNA was accomplished by analyzing the DNA on $0.8 \%$ agarose gel using diluted uncut lamda DNA as standard. DNA was diluted in TE buffer to a concentration of approximately 30ng/ $\mu 1$ for PCR analysis. The sequence information for the primer pairs was obtained from published sequence data (http://www.maizegdb.org/ ssr.php). A total of 75 hyper variable SSR primer pairs distributed across the 10 chromosomes were used for PCR amplification (Table 2).

\section{PCR amplification}

Seventy five SSR primer pairs were selected for this study. PCR was performed in a reaction mixture volume of $20 \mu \mathrm{L}$ containing of $30 \mathrm{ng}$ of template DNA, 1 x PCR buffer with $1.5 \mathrm{mM}$ of $\mathrm{MgCl}_{2}, 0.2 \mathrm{mM}$ of each dNTPs, 10 pmol of each primers and $1 \mathrm{U}$ of Taq DNA polymerase.

PCR was carried out in a Thermal Cycler programmed for 35 cycles of $95^{\circ} \mathrm{C}$ (5 min), $94^{\circ} \mathrm{C}(1 \mathrm{~min}) 56^{\circ} \mathrm{C}(30 \mathrm{Sec}),. 72^{0} \mathrm{C}(1 \mathrm{~min})$ then followed by final-extension at $72^{0} \mathrm{C}$ for 10 min. PCR products $(10 \mu \mathrm{l})$ were used for electrophoresis and the amplicons were resolved on $2.5 \%$ agarose gel stained with ethidium bromide at $1 \mu \mathrm{g} / \mathrm{ml}$, and visualized under UV in a gel documentation system and impurities were identified based on deviations in expected amplification pattern.

\section{Results and Discussion}

Characterization and identification of cultivars is crucial to varietal improvement, release and in seed production programme. It is mandatory to maintain the genetic purity of hybrid seed for the successful crop production. Unambiguous characteristic pattern of hybrids can be obtained using DNA markers and had been termed as DNA fingerprinting. The use of DNA markers to obtain genotype specific profiles had distinct advantages over morphological and biochemical methods. The morphological markers are influenced by the environmental conditions, labour intensive and time consuming. However, the biochemical markers such as isozyme and protein patterns are least influenced by the environment but exhibit limited polymorphism and often do not allow discrimination between closely related inbred lines (Lucchese et al., 1999).

DNA markers overcome most of these disadvantages of morphological and biochemical markers that can be useful to distinguish varieties and off types. The usefulness of DNA fingerprinting technique for cultivar identification was demonstrated by Dallas (1988) for the first time in rice. The present study utilized the SSR marker techniques for identification of the maize hybrids along with their parental lines, demonstrating that this technique can be successfully applied to distinguish and identify the hybrids from its parental lines. SSR had much more polymorphism than most of other DNA markers, and is co-dominant and large in quantity. Therefore, the high polymorphic information content (PIC) of SSR had promoted the application of microsatellites as molecular markers in fingerprinting (Ashikawa et al., 1999). In this study primer pairs of 75 SSRs associated with each hybrid and parental lines were assessed on 2.5 per cent agarose. 
Fig.1 Polymorphic SSR marker profile confirm hybridity of HQPM1 with pumc1064; L: 100bp ladder, lane 1: HKI 193-1, lane 2: HKI 163, lane 3: HQPM1

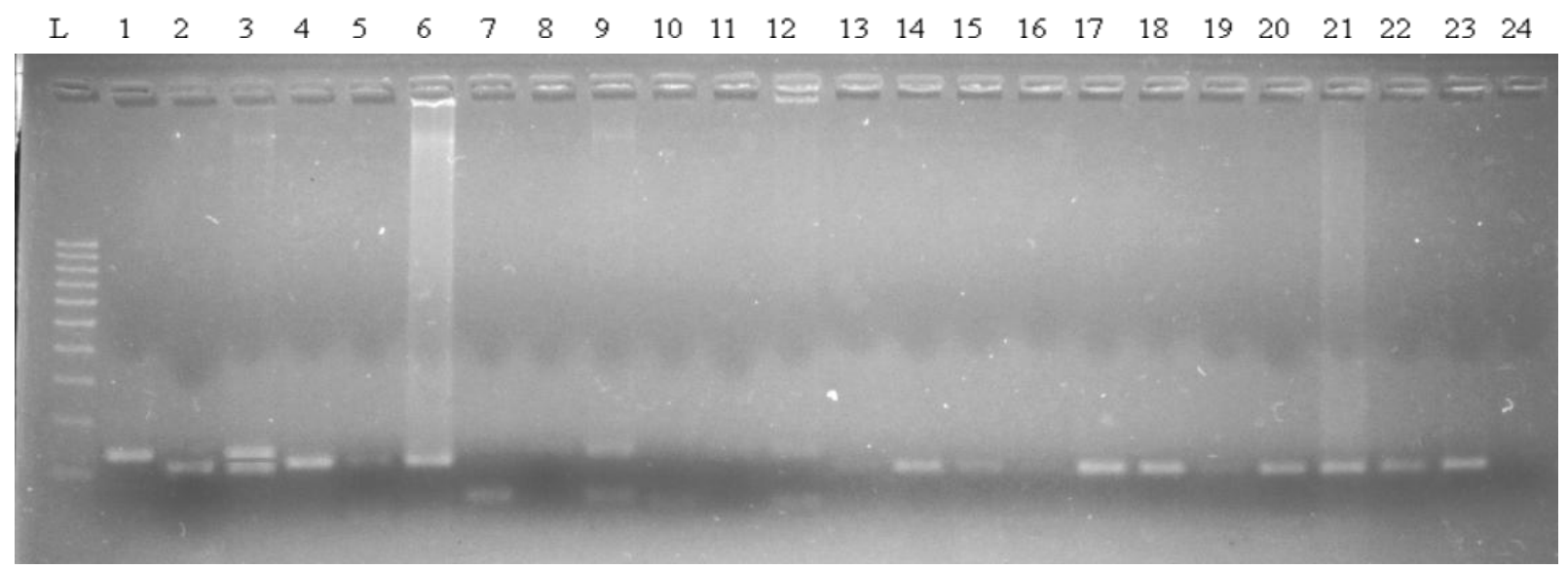

Fig.2 Polymorphic SSR marker profile confirm hybridity of HQPM4 and HQPM7 obtained with pumc1013; L: 100bp ladder, lane 4: HKI 193-2, lane 5: HKI 161, lane 6: HQPM4, lane 10: HKI 193-1, lane 11: HKI 161, lane 12: HQPM7

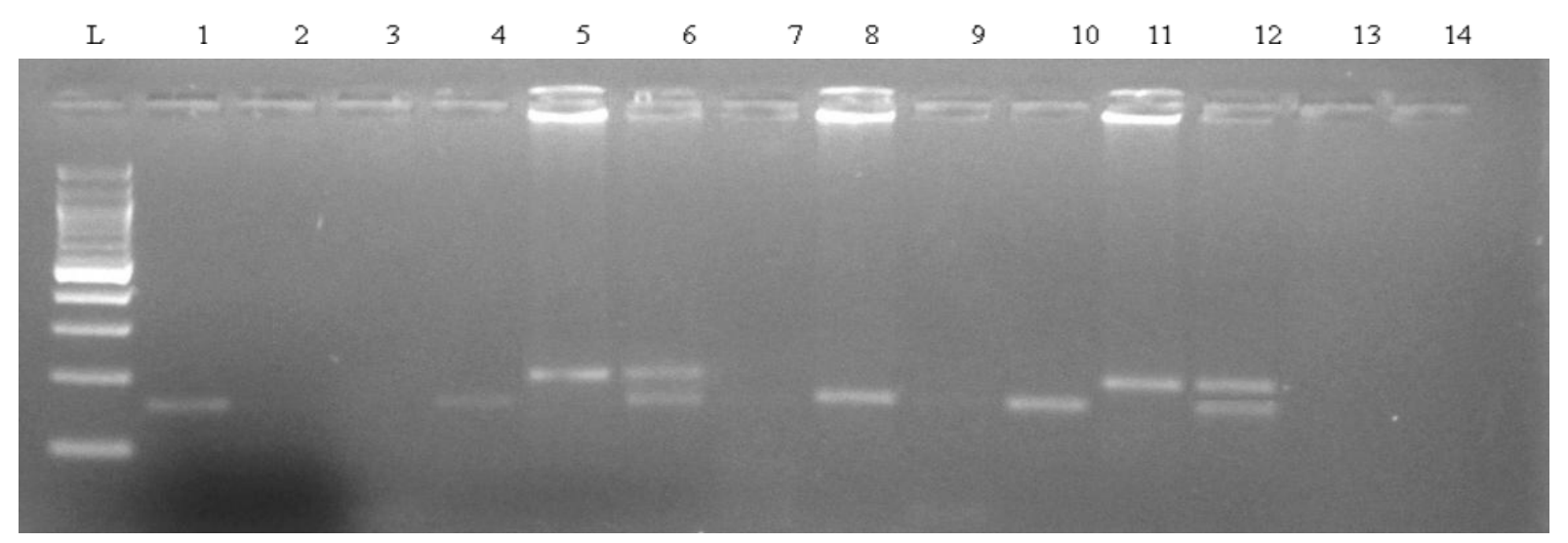

Fig.3 Polymorphic SSR marker profile confirm hybridity of HQPM4 and HQPM5 obtained with pumc1746; L: 100bp ladder, lane4: HKI163, lane5: HKI161, lane6: HQPM4 lane7: HKI163, lane8: HKI161, lane 9:HQPM5

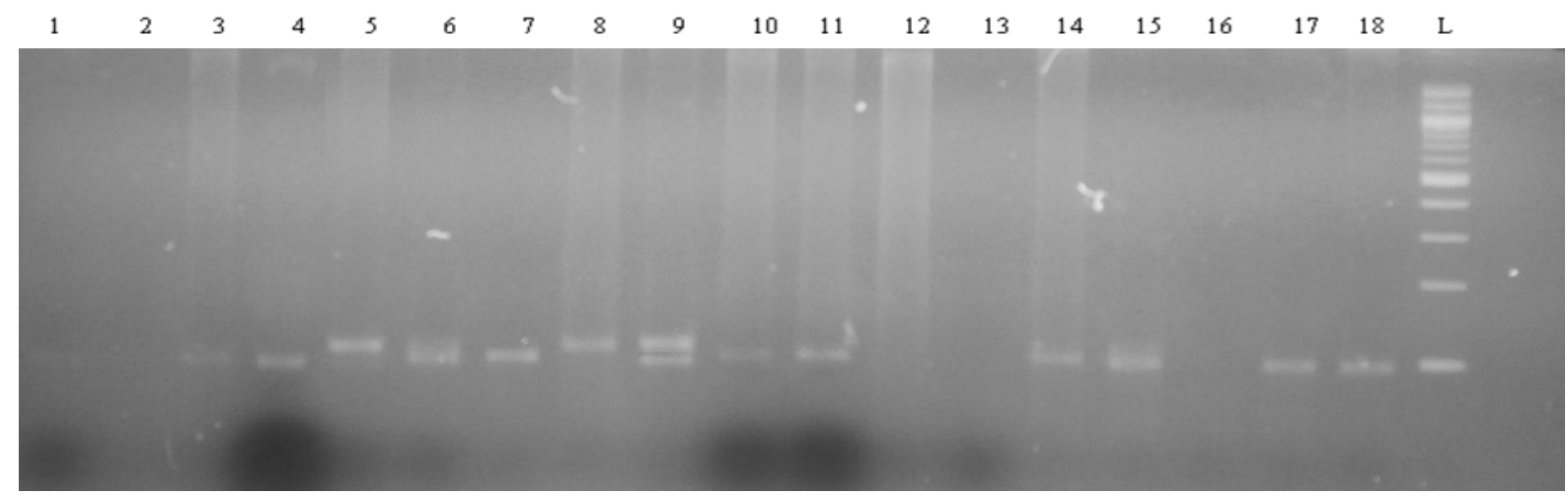


Fig.4 Polymorphic SSR marker profile confirm hybridity of HQPM 7 obtained with pumc1071; L: 100bp ladder, lane 10: HKI 193-1, lane 11: HKI 161, lane 12: HQPM7

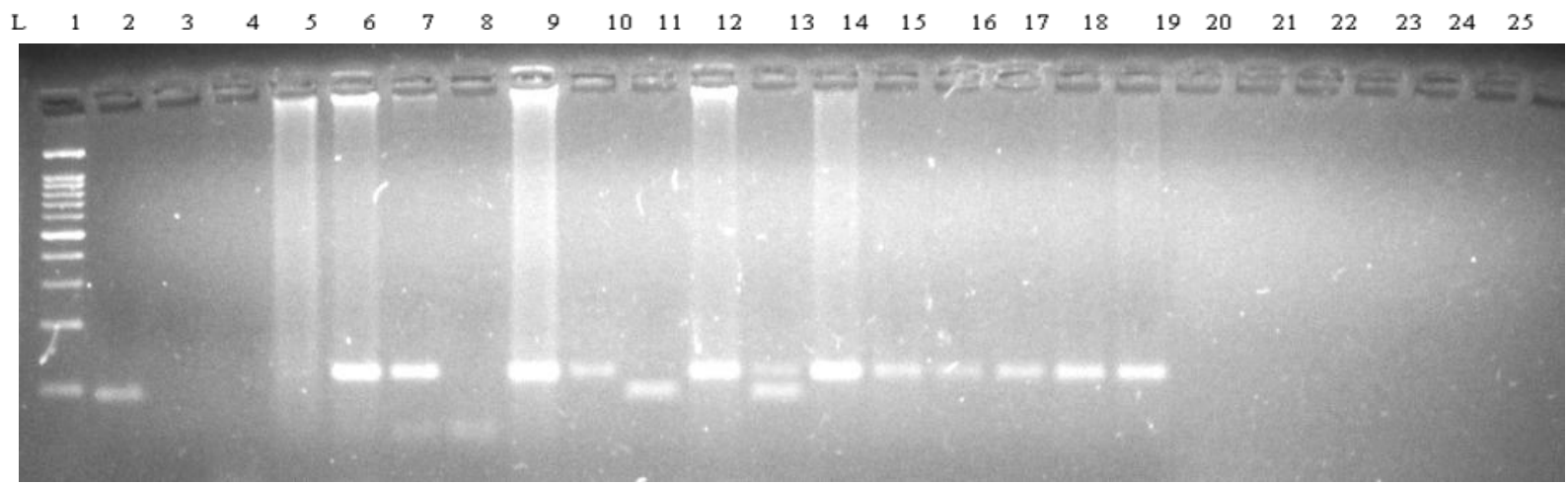

Fig.5 Polymorphic SSR marker profile confirm hybridity of HM2 with pumc1064; L: 100bp ladder, lane16: HKI 1352, lane17: HKI 1344, lane=18: HM2

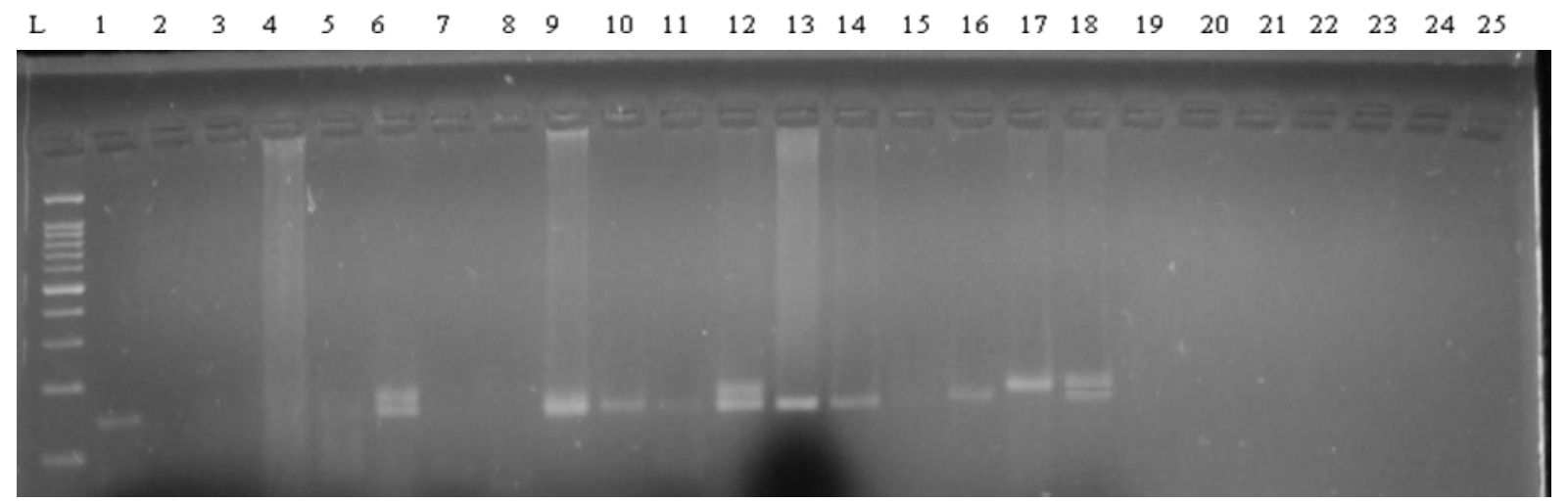

Fig.6 Polymorphic SSR marker profile confirm hybridity of HM 4 and HM 2 obtained with pumc1040; L: 100bp ladder, lane13: HKI 1105, lane14: HKI 323, lane15: HM4, lane16: HKI 1352, lane17: HKI 1344, lane18: HM2

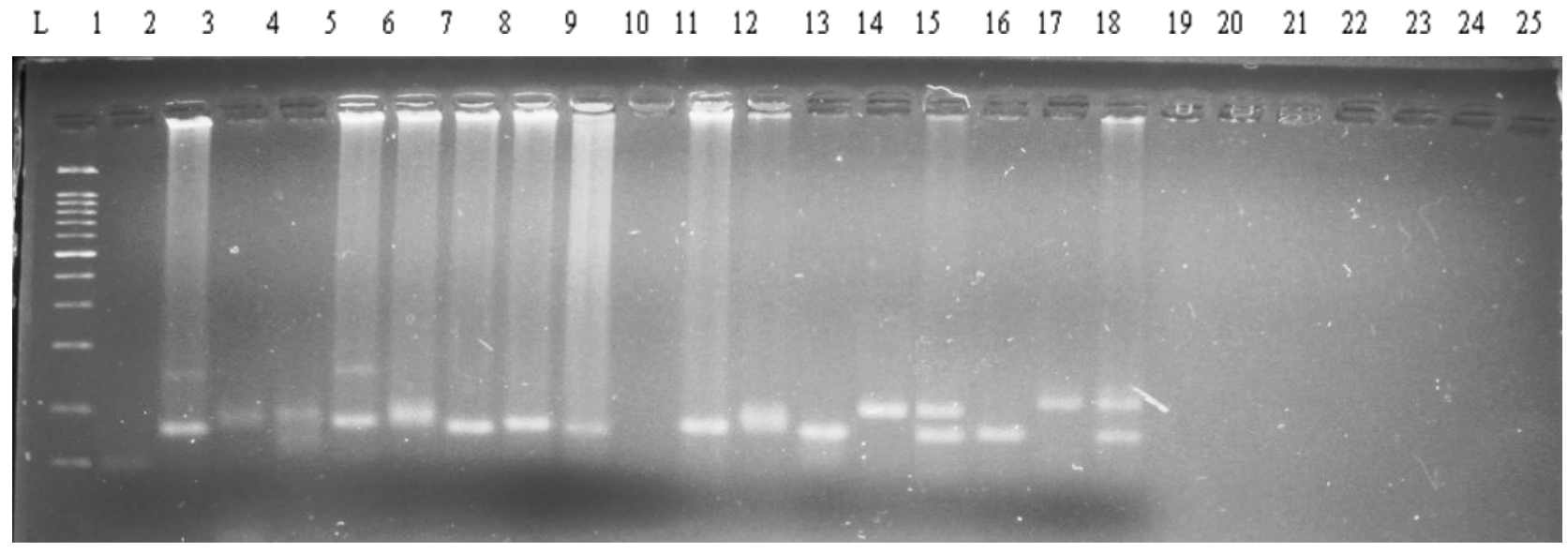


Table.1 Different hybrids along with their parental lines used in the present study

\begin{tabular}{|l|l|l|l|}
\hline S. No. & Hybrid & Parent 1 & Parent 2 \\
\hline $\mathbf{1}$ & HQPM1 & Hki $193-1$ & Hki 163 \\
\hline $\mathbf{2}$ & HQPM4 & Hki $193-2$ & Hki 161 \\
\hline $\mathbf{3}$ & HQPM5 & Hki 163 & Hki 161 \\
\hline $\mathbf{4}$ & HQPM7 & Hki $193-1$ & Hki 161 \\
\hline $\mathbf{5}$ & HM2 & Hki 1352 & Hki 1344 \\
\hline $\mathbf{6}$ & HM4 & Hki 1105 & Hki 323 \\
\hline
\end{tabular}

Table.2 SSR markers used in the study

\begin{tabular}{|c|c|c|c|c|c|}
\hline $\begin{array}{l}\text { S. } \\
\text { No. }\end{array}$ & SSR & Repeat motif & $\begin{array}{l}\text { Primer sequence }\left(5^{\prime}-3^{\prime}\right) \\
\text { Forward }\end{array}$ & $\begin{array}{l}\text { Primer sequence }\left(5^{\prime}-3^{\prime}\right) \\
\text { Reverse }\end{array}$ & $\begin{array}{l}\text { Chromosome } \\
\text { location }\end{array}$ \\
\hline 1. & p-umc 1009 & $(G T) 7(G A) 7$ & AGCAGCTCTGGTGATGGAAGAA & ATCCTAACAGGCGCATACCAGA & 1 \\
\hline 2. & p-umc1013 & $(G A) 9$ & TAATGTGTCCATACGGTGGTGG & AGCTGGCTAGTCTCAGGCACTC & 1 \\
\hline 3. & p-umc1021 & $(G T) 14$ & AGCCTCCTGAGACCTCTCGATT & ACTTCGCCACCTTACATTCTTGA & 1 \\
\hline 4. & p-umc1035 & $(C T) 19$ & CTGGCATGATCACGCTATGTATG & TAACATCAGCAGGTTTGCTCATTC & 1 \\
\hline 5. & p-umc1070 & $(T C) 7$ & GGTCTCTCTATCGTCCGGTGAGTA & CCGGAGATGGGAAAGAAGATAAC & 1 \\
\hline 6. & p-umc1071 & $(T A C G A) 5$ & AGGAAGACACGAGAGACACCGTAG & GTGGTTGTCGAGTTCGTCGTATT & 1 \\
\hline 7. & p-umc1082 & $(G A) 16$ & CCGACCATGCATAAGGTCTAGG & GCCTGCATAGAGAGGTGGTATGAT & 1 \\
\hline$\overline{8 .}$ & p-umc 2363 & $(A T G T) 4$ & TTGACTCGAAAGACTTGTGAGCTG & GTGTGTCAGAAGGAGGACTGATGA & 2 \\
\hline 9. & p-umc1227 & $(A G G) 4$ & CAAGTTGGTGAGATGGATCTGTTG & GCTCCTGGGTCTTCCTCTCC & 2 \\
\hline 10. & p-umc 1552 & $(G G A) 7$ & CTCGATAGCTCTGCTGCTTCCTC & CAACACCAGCCCTACCCAGA & 2 \\
\hline 11. & p-umc1823 & $(T G) 36$ & AAAGCCTTACTGTTATTAGGCTAGGCA & AGAAAACCAGCCCCAGATGTTC & 2 \\
\hline 12. & p-umc2186 & $(C G G) 6$ & CTCCCGCAGTCTATGAAGCTCAC & СТССТCTTCСТCСТCСТCGTTGT & 2 \\
\hline 13. & p-umc2193 & $(T C C) 6$ & CCGAGGCATACGGACAATACC & GTAGGAGGACGGGTGCTGGT & 2 \\
\hline 14. & p-umc2245 & $(C A A) 7$ & GCCCTGTTATTGGAACAGTTTACG & CGTCGTCTTCGACATGTACTTCAC & 2 \\
\hline 15. & p-umc2246 & $($ ССТССТ $) 4$ & AGGCTCCAGCTCTAGGGGAGT & GTGAACTGTGTAGCGTGGAGTTGT & 2 \\
\hline 16. & p-umc1057 & $(C G G) 6$ & GCCACGCTCAACTACGACAAC & GAACCCCTCCACGTAGCTCAG & 3 \\
\hline 17. & p-umc1183 & $(A G) 15$ & ATGTCATTTTTGGCTTCTCGAAAT & GCATGTACACAACACAACCTTTCA & 3 \\
\hline 18. & p-umc1458 & $(G C T) 5$ & ССААТАAАСАAАТСАТСТСССССТ & TGCTATGCTATGTACAGGGACAGG & 3 \\
\hline 19. & p-umc1746 & $(C A C) 4$ & ACACGAGCATCCTACATCCTCCTA & ACCTTGCCTGTCCTTCTTTCTCTT & 3 \\
\hline 20. & p-umc1793 & $(A T) 6$ & TGCACACCCTTTATTGAATCATCA & CGTATAAGCTTTTTGGGGTCCTCT & 3 \\
\hline 21. & p-umc1814 & $(C G A) 4$ & AGAAGAAGAGGAGGTTCCATGACC & GCATGTTTCCCTTTCACCTCC & 3 \\
\hline 22. & p-umc1886 & $(C G) 8$ & GTTTGACAGCACAAGTGCAAGAAA & GAGGTGGACATTGGACAACACC & 3 \\
\hline 23. & p-umc 1892 & $(G A) 8$ & AGCTGCAAAAGCAAGTGAAACAAT & TCTCCTCGATCGTTGTATGTGTGT & 3 \\
\hline 24. & p-umc1228 & $(C A G) 8$ & TCCTCAAGGACCTGCTCCAC & ACCTATACAGACGGAGACGGGG & 4 \\
\hline 25. & p-umc1232 & $(A C A G) 4$ & GGAATTACCACAACAAACTAAACTTGG & AGGCTCTAGCTACCTGGCTACGTT & 4 \\
\hline 26. & p-umc1561 & $(T T T A) 4$ & TCTCTTCATCTCAGCATCTCTCCA & TATTGTGATGTGAGCTGCATTGG & 4 \\
\hline 27. & p-umc1669 & $(A G A) 4$ & ACGAGGGCTTCTTCTCTGAGC & GTTTCCTTCTTCATGCGACGAC & 4 \\
\hline 28. & p-umc1842 & $(A G) 16$ & CCACCTGCACAACACACATAAAAC & GTGGTGGAGTCGCTAAGTCAGGT & 4 \\
\hline 29. & p-umc 1758 & $(C T T) 5$ & СТTССТССТСАССТСАССТССТАТ & GGTAGCCAATCCTTCCTTCCTATG & 4 \\
\hline 30. & p-umc2278 & $($ TCTC $) 4$ & CTGACCTCCGTCATCAGCATC & ATCACGGACAAAGAAAATTGAAGC & 4 \\
\hline 31. & p-umc1834 & $(A T) 8$ & AAGATAATGCAACCCTGGACAAAA & TTGCGGATCTGTTAAGGTGACATA & 4 \\
\hline 32. & p-umc1631 & $(A T G T) 8$ & CATGAATAAAGATGGATGCTGGTG & GGAAAAACAAAGAAGCATAGTAGACAGC & 4 \\
\hline 33. & p-umc 1086 & $(C T) 12$ & CATGAAAGTTTTCCTGTGCAGATT & GGGCAACTTTAGAGGTCGATTTATT & 4 \\
\hline 34. & p-umc2291 & $(C C T) 5$ & CTCGACGAGTTCAAGCGCTAC & AACTTCTCCTGGCGAGCATCT & 5 \\
\hline 35. & p-umc2292 & $(C T G C C T) 4$ & AGCAGAAGAGGACAAACCAGATTC & ACTTCCGGCATGTCTTGTGTTT & 5 \\
\hline 36. & p-umc 1853 & $(G T) 8$ & TTATTATTAACACCTGCCTGCGCT & GCTAGCTAGGAAACATGGCTTGTC & 5 \\
\hline 37. & p-umc1423 & $(C T A G) 4$ & TAGTATGGTCCATTGATGCTGGC & GAGCAGGCGGAGGATACTAGC & 5 \\
\hline 38. & p-umc1155 & $(A G) 20$ & TCTTTTATTGTGCCCGTTGAGATT & CCTGAGGGTGATTTGTCTGTCTCT & 5 \\
\hline 39. & p-umc1491 & $(A G A) 5$ & TAATAATCCCAAACCACCAAAAGG & GATTTGAGGCCATAGTGCTCCTTA & 5 \\
\hline 40. & p-umc1496 & $(G C A) 8$ & GATTACAACCCACCGGAGTTACAG & GCTCTTCCTAGGTGCAGACAAAGA & 5 \\
\hline 41. & p-umc1679 & $(A A G) 5$ & CACTGCTAAGCTGCTCCCTGTT & TGCTAACTAACCCTGACCCTCTCA & 5 \\
\hline 42. & p-umc 2022 & $(A G C G) 4$ & TTAGTCTAACCGAGTCCAACCAGTG & ACCAGCAGACGGAGAGCTTG & 5 \\
\hline 43. & p-umc 1002 & (TA) 10 & AGCTAGCTATACACCGCCAGG & TCAGTTTGGAACAGGGAAAAGTA & 6 \\
\hline 44. & p-umc1006 & $(G A) 19$ & AATCGCTTACTTGTAACCCACTTG & AGTTTCCGAGCTGCTTTCTCT & 6 \\
\hline
\end{tabular}




\begin{tabular}{|l|l|}
\hline p-umc1018 & $(C T) 7$ \\
\hline p-umc1020 & $(C T) 8$ \\
\hline p-umc1023 & $(A T) 11$ \\
\hline p-umc1083 & $(G A) 16$ \\
\hline p-umc1114 & $(A G A A) 6$ \\
\hline p-umc1546 & $(G A G) 5$ \\
\hline p-umc1133 & $A T A C$ \\
\hline p-umc1066 & $(G C C A G A) 5$ \\
\hline p-umc1159 & $(A G) 8$ \\
\hline p-umc1241 & $(G T C T T T G) 4$ \\
\hline p-umc1378 & $(C G C) 6$ \\
\hline p-umc1577 & $(C T T G G C) 4$ \\
\hline p-umc1583 & $(G A A) 4$ \\
\hline p-umc1545 & $(A A G A) 4$ \\
\hline p-umc2042 & $(G C C) 4$ \\
\hline p-umc1034 & $G A(12)$ \\
\hline p-umc1414 & $(G C T A) 4$ \\
\hline p-umc1786 & $(T C) 7$ \\
\hline p-umc1868 & $(A T) 8$ \\
\hline p-umc1064 & $(C T) 8$ \\
\hline p-umc1279 & $(C C T) 6$ \\
\hline p-umc2335 & $(T G) 6$ \\
\hline p-umc1809 & $(G G A) 5$ \\
\hline p-umc1867 & $(T C) 8$ \\
\hline p-umc2084 & $(C T A G) 4$ \\
\hline p-umc1038 & $(C T) 15$ \\
\hline p-umc1054 & $(C A G) 6$ \\
\hline p-umc1077 & $(C A) 15(C G C A) 12$ \\
\hline p-umc1084 & $(C T) 23$ \\
\hline p-umc1115 & $(A G) 6$ \\
\hline p-umc1239 & $(T G) 6$ \\
\hline
\end{tabular}

GAACGGATATTGGAACCTGTGC CCTGGAGAGCCACTACAAGGAA CTTGTGCCACCACATGCAGTA CTTTCCTCTCTGGAGCGTGTATTG CAATGTGTTATTGATTGTACACCGC CTGGTCTTGGCCTTGGACTTCT ATTCGATCTAGGGTTTGGGTTCAG ATGGAGCACGTCATCTCAATGG TTCCCATGTTCATTTCAGGTTCTT TGAAGCAAGTCACTGGTAAGAGCA GAAGTCGCTGATGAGAACGTAACC TTTCCCTTCTTGGCAGGAGC AAAGGGCGACTTGTTTTTGTTTTT GAAAACTGCATCAACAACAAGCTG GCAGTCTCTCCACTACCAGAGCAT GTGTTTCCGTTTCGCTGATTTTAC CGATCATCTCTCACTCTCTCGTCA ACCGTGACTTCCTCCTCATAACTG CCATCATGGAGTTGCGGTTATTTA GTGGGTTTTGTCTGTAGGGTGGTA GATGAGCTTGACGACGCCTG ATTCAGTTTGTAATTGTCGGTGGG ACTCTTCTTCTTCCACCGGGAC TGGTCTTCTTCGCCGCATTAT ATCGCGACGAGTTAATTCAAACAT CGTCACACTCCTCTGCCACTT CCGTCTTCTTCAGGGTGTTCC CAGCCACAGTGAGGCACATC GATAAAAAGGCAAGTGCAACAAGG TGGAAGGGGATATCAGGATTTAGA ATCAACACACCTTTCGATTTCTGG

\begin{tabular}{|l|l|}
\hline GTGCACGGTGTCGTACTTGAAC & 6 \\
\hline TCAGCCTGAGCTCACATCATCT & 6 \\
\hline CAGTTTGAACAGGGAAAAGTACG & 6 \\
\hline ATATGTTGCAGAACCATCCAGGTC & 6 \\
\hline ACAGCAGGAGGCAGAGACTGAC & 6 \\
\hline GTCACAGCAAAGTCATCCTCCTCT & 7 \\
\hline GATGCAGTAGCATGCTGGATGTAG & 6 \\
\hline AGCAGCAGCAACGTCTATGACACT & 7 \\
\hline TCATGGGTTTGAGGCTGTATTT & 7 \\
\hline TGACACACCCATACTTCCAACAAG & 7 \\
\hline GCTAGCTAGTGTGAGTTCTTCCG & 7 \\
\hline AAGAACTCCTTCAAGCTGCCG & 7 \\
\hline GCCTGCTTTTTGTATCTTAGGCA & 7 \\
\hline ATTGGTTGGTTCTTCTTCCATTA & 7 \\
\hline AACAGAGGAGTACGAGGAGGAGC & 8 \\
\hline TCATCCATGTGACAGAGACGACTT & 8 \\
\hline GTTGACGACGTCTGGCTCCT & 8 \\
\hline CATTTTCGCATTTAGGAAATCCA & 8 \\
\hline CCCATAGAGTGCTTGAAATTGTTGA & 8 \\
\hline TCCATCCACTCGACTTAAGAGTCC & 1 \\
\hline CAATCCAATCCGTTGCAGGTC & 9 \\
\hline AATCACTATCATTACTGGCTGGGC & 9 \\
\hline GTCGGACTCGAGAAACGACG & 9 \\
\hline ATAAGCTCGTTGATCTCCTCCTCC & 9 \\
\hline TACGATGTCTTCAGTGTGACACCA & 9 \\
\hline GAGGATTCAGAACTCGACTCGG & 10 \\
\hline GTGGAGTTAGTAGGGTCGTTGCAC & 10 \\
\hline CAGAGACTCTCCATTATCCCTCCA & 10 \\
\hline ATATCAACCAGAGGCTGGAACTTG & 10 \\
\hline TGTGATGACCATGAATGTAAGCTG & 10 \\
\hline CGGTGATTAGTCGATGAAGAGTGA & 10 \\
\hline
\end{tabular}

Table.3 SSRs identifying different hybrids along with the size of the amplified alleles

\begin{tabular}{l|l|l|l|}
\hline $\begin{array}{l}\text { Hybrid } \\
\text { HQPM1 }\end{array}$ & $\begin{array}{c}\text { Size of the amplicon } \\
\text { in Parent } 1\end{array}$ & $\begin{array}{l}\text { Size of the amplicon } \\
\text { in Parent } 2\end{array}$ & Hybrid Identifying SSR/(s) \\
\hline HQP & $100 \mathrm{bp}$ & pumc1064 \\
\hline HQPM4 & $180 \mathrm{bp}$ & $200 \mathrm{bp}$ & pumc1013 \\
\hline HQPM5 & $100 \mathrm{bp}$ & $130 \mathrm{bp}$ & pumc1746 \\
\hline HQPM7 & $100 \mathrm{bp}$ & $130 \mathrm{bp}$ & *pumc1071, pumc1066 \\
\hline HM2 & $150 \mathrm{bp}$ & $170 \mathrm{bp}$ & pumc1035 \\
\hline HM4 & $150 \mathrm{bp}$ & $200 \mathrm{bp}$ & pumc1040 \\
\hline *Both these SSRs produced same size of amplicons \\
These SSRs can be used to differentiate hybrids from their parents
\end{tabular}

The PCR products of the DNA samples on the agarose did appeared and showed polymorphism among the hybrid and their parental lines. Among the 75 primers studied, eight primers viz., pumc1064, pumc1013, pumc1746, pumc1071, pumc1066, pumc1040, pumc1023 and pumc 1035 showed polymorphism between the parental lines which were used for the production of maize hybrids and rest of primers showed monomorphic banding pattern (Table 3 ).

The SSR primer pumc1064 amplified a specific allele of size $130 \mathrm{bp}$ in HQPM-1 and its female parent Hki193-1 but not in pollen parent Hki163. While the allele size of $100 \mathrm{bp}$ was present in pollen parent. The same allele size of $100 \mathrm{bp}$ has also appeared in $\mathrm{F}_{1}$ hybrid 
but not in female parent (Figure 1). Thus, it confirmed that the presence of both female and male parent alleles was observed as a resultant of crossing between two parents $\left(\mathrm{F}_{1}\right.$ hybrid). Similarly pumc1013 maker had also resulted in amplifying allele of size $180 \mathrm{bp}$ in female parent (Hki193-2) which was absent in pollen parent (Hki 161). While, the pollen parent had an amplicon at $200 \mathrm{bp}$ which was absent in female parent. However, the hybrid HQPM-4 exhibited both the alleles of the parents confirming the heterozygosity condition of the hybrid by having bands at 180 and $200 \mathrm{bp}$ (Figure 2). The identified SSRs in $F_{1}$ hybrids showed complementary banding pattern of both the parents. Hybrid HQPM-5 could be identified and distinguished by the SSR marker pumc1746 (Figure 3), HQPM-7 by pumc1071 (Figure 4) and pumc1066, HM-2 by pumc1064 (Figure 5) and HM-4 by pumc1040 (Figure 6).

The banding pattern of all these hybrids showed both the amplicons present in female as well as pollen parent, thus confirming the genuine crossing and heterozygotic condition of the hybrid. The SSR markers identified had both female and male specific bands and are useful in genetic purity testing. The use of SSR markers for genetic purity testing has already been demonstrated in maize (Daniel et al., 2012; Mrutu, 2015; Simon and Lovasz, 2016; Wu et al., 2010); rice (Bora et al., 2016; Galal et al., 2014; Moorthy et al., 2011; Sudharani et al., 2013), pearl millet (Nagawade et al., 2016), eggplant (Reddy et al., 2015), soybean (Zhang et al., 2014), cauliflower (Zhao et al., 2012) and in sunflower (Pallavi et al., 2011).

The present study showed that SSR markers are quick, effective and results are generally consistent with morphological analysis in the field study. Primers identified in the study could be utilized for routine genetic purity testing of these maize hybrids. The SSR marker information developed through this study will be of immense help for hybrid maize seed industry to select appropriate marker combinations and assess genetic purity of the crop.

\section{References}

Alireza, S. (2014). Isozymes and purity analysis in the sunflower (Helianthus annuus L.) three hybrids Lotto7R0, Lotto7R09 and LottoR02. Biotechnology, 13, 135-138. DOI: 10.3923/biotech.2014.135.138

Ashikawa, I., Kurata, N., Saji, S., Umehara, Y., Sasaki, T. (1999). Application of restriction fragment fingerprinting with a rice microsatellite sequence to assembling rice YAC clones. Genome, 42, 330-337.

Bora, A., Choudhury, P.R., Pande, V. And Mandal, A.B. (2016). Assessment of genetic purity in rice (Oryza sativa L.) hybrids using microsatellite markers. Biotechnology, 6 (1), 50. DOI 10.1007/s13205-015-0337-y

Dallas, J.F. (1988). Detection of DNA "fingerprints" of cultivated rice by hybridization with a human minisatellite probe. Proceedings of the National Academy of Sciences, USA, 85, 86316835.

Daniel, I.O., Adetumbi, J.A., Oyelakin, O.O., Olakojo, S.A., Ajala, M.O. and Onagbesan, S. (2012). Application of SSR markers for genetic purity analysis of parental inbred lines and some commercial hybrid maize (Zea mays L.). American Journal of Experimental Agriculture, 2, 597-606.

Dongre, A.B., Raut, M.P., Paikrao, V.M., Pande, S.S. (2012). Genetic purity testing of cotton $\mathrm{F}_{1}$ hybrid DHH-11 and parents revealed by molecular markers. International Research Journal of Biotechnogy, 3, 32-36. 
Dongre, A.B., Rout, M.P., Bhandarkar, M.R. and Meshram, K.J. (2011). Identification and genetic purity testing of cotton $F_{1}$ hybrid using molecular markers. Indian Journal of Biotechnology, 10, 301-306.

Dou, X., Yan, M., Xu, Y., Hussain, K., Liu, Y. and Lin, F. (2010). Identification of seed purity of maize hybrids by ultrathin layer isoelectric focusing electrophoresis of seed salt soluble proteins. Middle-East Journal of Scientific Research, 6(4), 382-385.

Doyle, J.J., Doyle, J.L. (1990). Isolation of plant DNA from fresh tissue. Focus, 12, $13-15$.

Galal, O.A., Mahmoud, I.A.Y., Mona, A., Ahmed, T.G. and Said, A.D. (2014). Assessment of genetic purity of some hybrid rice parental lines using protein profile and fertility restorer gene linked markers. International Journal of Biotechnology Research, 2(6), 75-88.

Liu, L. and Wang, Y. (2000). Identification of maize seed purity based on electrophoresis. Seed Word, 21.

Lucchese, C., Dinelli, G., Miggiano, A., Lovato, A. (1999). Identification of pepper (Capsicum spp.) cultivars by field and electrophoresis tests. Seed Science and Technology, 27, 37-47.

Moorthy, K.K., Babu, P., Sreedhar, M., Sama, V., Kumar, P.N., Balachandran, S.M., Sundaram, R.M., (2011). Identification of informative EST-SSR markers capable of distinguishing popular Indian rice varieties and their utilization in seed genetic purity assessments. Seed Science and Technology, 39, 282-292.

Mrutu, B.A. (2015). Assessment of seed genetic purity of hybrid maize variety UH6303 in southern highlands of Tanzania by random amplified polymorphic DNA (RAPD) markers. African Journal of Agricultural
Research, 10(30), 2911-2918. DOI: 10.5897/AJAR2014.8600

Nagawade, D.R., Markad, N.R. and Patil, H.T. (2016) Hybridity and genetic purity testing of pearl millet Pennisetum glaucum (1.) r. br.] hybrid Shraddha. In: Proceedings of $60^{\text {th }}$ IRF International Conference, 24th July, 2016, Pune, India, ISBN: 978 -93-86083-70-8

Paliwal, R.L., Granados, G., Lafitte, H.R., Violic, A.D. and Marathee, J.P. (2000). Tropical Maize: Improvement and Production, Food and Agriculture Organization of the Unites Nations, Rome, Italy.

Pallavi, H.M., Rame, G., Shadakshari, Y.G., Bhanuprakash, K., Vishwanath, K. (2011). Identification of SSR markers for hybridity and seed genetic purity testing in sunflower (Helianthus annuus L.). Helia, 34, 59-66.

Reddy, D.C., Khandagale, K., Reddy, S.H.S., Kanupriya, C., Aswath, C., and Singh, T.H. (2011). SSR-based DNA barcodes as a tool for identification of eggplant genotypes. International Journal of Vegetable Science, 18(3), 260-271.

Reddy, D.C., Khandagale, K., Victorathisayam, T., Aswath, C., and Singh, T.H. (2015). Genetic purity of interspecific hybrids of Solanum melongena and $S$. macrocarpon assessed using SSR markers International Journal of Vegetable Science, 21, 111-117. DOI: org/10.1080/19315260.2013.837133

Simon, Z. and Lovász, C. (2016). Genetic purity testing of maize hybrids using a MALDI-TOF mass spectrometric method. Journal of food investigation, 2 ,

Sinha, K.N., Singh, M. and Kumar, C. (2012). Electrophoretic study of seed storage protein in five species of Bauhinia sp. International Journal of Pharma and Bio Sciences, 4(2), 8-11. 
Sudharani, M., Rajya Lakshmi, K., Vishnuvardhan, A.R., Bharthi, K., RamaRaju, N. (2013). Use of DNA polymorphism for characterization and assessment of genetic purity testing in rice hybrids (Oryza sativa L.). Electronic Journal of Plant Breeding, 2, 1113-1118.

Wu, M., Jia, X., Tian, L. and Lv, B. (2010). Rapid and reliable purity identification of $\mathrm{F}_{1}$ hybrids of maize (Zea may L.) using SSR markers. Maize Genomics and Genetics, 1 (1), doi: 10.5376/mgg.2010.01.0001
Zhang, C.B., Peng, B., Zhang, W.L., Wang, S.M., Sun, H., Dong, Y.S., and Zhao, L.M. (2014). Application of SSR Markers for purity testing of commercial hybrid soybean (Glycine max L.) Journal of Agriculture Science and Technology, 16, 1389-1396

Zhao, Z., Gu, H., Sheng, X., Yu, H., Wang, J. and Cao, J. (2012). Genetic purity testing of loose-curd cauliflower hybrids using SSR markers and Grow out Test. Seed Science and Technology, 40, 209-214.

\section{How to cite this article:}

Shalu Chaudhary, Shikha Yashveer, Dinesh, Deepak Raj Prajapati, Pushpa Kharb and Mehar Chand Kamboj. 2018. Utilization of SSR Markers for Seed Purity Testing in Popular Maize Hybrids. Int.J.Curr.Microbiol.App.Sci. 7(04): 1117-1126. doi: https://doi.org/10.20546/ijcmas.2018.704.122 